\title{
QUALIDADE FISIOLÓGICA DE SEMENTES DE FEIJÃO ENVELHECIDAS EM CONDIÇÕES DE ALTA TEMPERATURA E UMIDADE RELATIVA
}

\section{PHYSIOLOGICAL QUALITY OF BEAN SEEDS AGED UNDER HIGH TEMPERATURE AND RELATIVE HUMIDITY}

\author{
Angelica Buzinaro Avaci, Silvia Renata Machado Coelho, Lúcia Helena \\ Pereira Nóbrega, Danielle Medina Rosa, Divair Christ
}

Universidade Estadual do Oeste do Paraná - UNIOESTE

e-mail: angelicaavaci@gmail.com

Recebido para publicação em: 05/02/2010

Aceite para publicação em: 01/04/2010

\section{RESUMO}

O feijão comum é um alimento tradicional da alimentação humana e durante o armazenamento das sementes ocorre perda de qualidade, cujo grau de intensidade depende de diferentes fatores. Assim, o objetivo deste trabalho é avaliar os efeitos do armazenamento em condições controladas de alta temperatura e umidade relativa na qualidade da semente do feijão. Foram utilizadas sementes da variedade do Uirapuru e Rio Vermelho, armazenadas a $40{ }^{\circ} \mathrm{C}$ e $76 \%$ de umidade relativa, e amostras retiradas aos zero (controle), 15 e 30 dias. Após cada tempo foram avaliados os parâmetros porcentagem de germinação, teor de água, massa de 100 sementes, envelhecimento acelerado, velocidade de emergência e condutividade elétrica. Observou-se que a variedade Uirapuru apresentou qualidade superior à variedade Rio Vermelho em todos os parâmetros avaliados, exceto no teste de condutividade elétrica, e que o aumento do tempo de armazenamento afetou negativamente a qualidade fisiológica das sementes. Conclui-se que o armazenamento em condições de alta temperatura e umidade relativa prejudica a qualidade da semente e, consequentemente, a produção no campo.

Palavras-chave: Phaseolus vulgaris. Armazenamento. Germinação.

\begin{abstract}
The common bean is a traditional food in human diet. During bean storage the quality of the seeds deteriorates and its intensity depends on different factors. This work was carried to evaluate the effects of storage under controlled temperature and high humidity on the quality of the bean seeds. Seeds of the varieties Uirapuru and Rio Vermelho, were stored at $40^{\circ} \mathrm{C}$ and $76 \% \mathrm{RH}$ and samples taken at zero (control), 15 and 30 days. After each period the germination
\end{abstract}


percentage, moisture content, weight of 100 seeds, accelerated aging, speed of emergence and electrical conductivity were evaluated. It was observed that the variety Uirapuru presented higher quality compared to the Red River variety in every test except the electrical conductivity and the increase of storage time negatively affected the physiological quality of seeds. It was concluded that the storage conditions at high temperature and relative humidity affect the quality of seed production and consequently the field production.

Keywords: Phaseolus vulgaris. Storage. Germination.

\section{INTRODUÇÃO}

Cultivado por pequenos e grandes produtores, em diversificados sistemas de produção e em todas as regiões brasileiras, o feijoeiro comum reveste-se de grande importância econômica e social. Além disso, seu papel relevante na alimentação do brasileiro e a mão-de-obra empregada durante o ciclo da cultura fazem com que o feijão seja um dos produtos de maior expressão nacional (EMBRAPA, 2008).

O Brasil é um dos maiores produtores de feijão do mundo (EMBRAPA, 2008). Somando-se todas as safras de feijão, o país contou com uma área plantada na safra 2009/2010 de quase 4 mil hectares, com produtividade média de $880 \mathrm{kgha}^{-1}$. Devido aos diferentes sistemas de produção dessa cultura, o Brasil apresenta produtividades que variam de 500 kg.ha-1, no Nordeste, a 1800 kg.ha-1, na região Centro-Oeste, e o potencial genético para a espécie é de $5000 \mathrm{~kg} \cdot \mathrm{ha}^{-1}$.

$\mathrm{O}$ esforço de pesquisas em obter melhores níveis de produtividade e garantir o abastecimento interno do produto é justificado pela importância social do feijão, como alimento protéico e rico em ferro e pelo consumo generalizado pela população brasileira (FRANCISCO et al., 2007). Menten et al. (2006) relataram baixa taxa de utilização de sementes legais dessa leguminosa. Dos 4,2 milhões de hectares cultivados na safra 2003/2004, $92 \%$ utilizaram como material de propagação sementes próprias, "salvas", "piratas" ou grãos, e apenas $8 \%$ da área foram cultivados com sementes legais. Essa, provavelmente, é uma das principais razões do baixo rendimento médio do feijoeiro no Brasil.

A qualidade fisiológica das sementes de feijão varia de acordo com o genótipo (SILVA et al., 2008), e a deterioração da qualidade pode ocorrer durante o armazenamento em condições inadequadas de tem- peratura e umidade relativa (SANTOS et al., 2005), a qual não pode ser evitada, mas apenas minimizada. As causas mais frequentes de perdas no armazenamento são os ataques de insetos, fungos e roedores, ocorrendo, também, perda da qualidade intrínseca, como a aparência e o sabor, no caso do feijão para consumo (BRAGANTINI et al., 2005; MARINO \& MESQUITA, 2009). Segundo Azevedo et al. (2003), quando se trata das sementes, existem perdas quanto à sua capacidade de germinar e produzir planta vigorosa e sadia, havendo necessidade de avaliação da qualidade fisiológica durante essa etapa, a fim de se obter a produtividade desejada. Além disso, a qualidade sanitária e o grau de umidade também devem ser avaliados no início do armazenamento (FRANCISCO, 2001). A obtenção de sementes de alta qualidade representa a meta prioritária dentro do processo de produção, pois, de um modo geral, a germinação e a emergência das plântulas são reflexos da qualidade fisiológica (ROSSETO et al.,1997).

Para Novembre e Marcos-Filho (1991), o armazenamento de sementes constitui-se numa etapa praticamente obrigatória devido à defasagem natural entre a colheita e a semeadura. A temperatura de armazenamento e a atividade de água no feijão são fatores-chave na velocidade e intensidade da perda de qualidade (SARTORI, 1996).

Coelho et al. (2009), ao compararem o armazenamento de feijão comum em condições ambiente e sob $76 \%$ de umidade relativa (UR) e $40^{\circ} \mathrm{C}$, concluíram que alterações nos grãos de feijão ocorridas durante o armazenamento por um ano em condições ambientais eram equivalentes às alterações ocorridas pelo armazenamento por 30 dias sob $76 \%$ de UR e $40^{\circ} \mathrm{C}$. Os referidos autores constataram que essas condições podem ser utilizadas para simular o efeito de armazenamento por um ano, obtendo-se respostas mais rápidas. 
O presente trabalho objetiva avaliar os efeitos da aceleração do envelhecimento com armazenamento a $76 \%$ de UR e $40^{\circ} \mathrm{C}$ por trinta dias na qualidade da semente do feijão.

\section{MATERIAL E MÉTODOS}

O experimento foi realizado no laboratório de sementes da Universidade Estadual do Oeste do Paraná-UNIOESTE, campus Cascavel. Foram utilizadas sementes de feijão comum (Phaseolus vulgaris), de variedades comercias (Uirapuru e Rio Vermelho) obtidas de produção comercial situada em Capitão

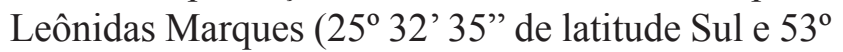
29'43" de longitude), na safra 2007/2008.

Um lote de sementes da variedade Uirapuru e da variedade Rio Vermelho foi submetido à aceleração do envelhecimento, a fim de simular armazenamento por cerca de um ano em condições ambientais. Para tanto, as sementes foram armazenados em recipientes fechados, contendo $600 \mathrm{~g}$ de amostra, mantidos a 76 $\%$ de umidade relativa (UR) e temperatura de $40{ }^{\circ} \mathrm{C}$, e as amostras foram coletadas aos 15 e 30 dias. $\mathrm{O}$ lote controle, considerado o tempo 0 , contendo $600 \mathrm{~g}$ de sementes de cada variedade, foi armazenado sob refrigeração. Para a obtenção da umidade relativa a $76 \%$, foi utilizada uma solução saturada de cloreto de sódio depositada nos recipientes que continham os grãos, os quais foram separados da solução por telas de plástico perfuradas (COELHO, 2009).

As análises de qualidade das sementes foram realizadas em todas as amostras, para cada tempo de armazenamento. $\mathrm{O}$ teor de água foi determinado pelo método da estufa à temperatura de $105^{\circ} \mathrm{C} \pm 3$ ${ }^{\circ} \mathrm{C}$, durante 24 horas, com duas amostras por cultivar. Para determinação da massa de 100 sementes foram usadas oito subamostras de 100 sementes provenientes da porção semente pura, em que as sementes foram contadas manualmente e, em seguida, pesadas (BRASIL, 1992).

No teste de germinação foram usadas quatro subamostras de 50 sementes, distribuídas em rolos de papel umedecidos com água destilada $(2,5$ vezes o peso do papel seco) e mantidas em germinador à temperatura de $25^{\circ} \mathrm{C}$, durante sete dias. A avaliação das plântulas normais foi realizada no sétimo dia após a instalação do teste (BRASIL,1992). Os resultados foram expressos em porcentagem.
No teste de envelhecimento acelerado, quatro subamostras de 200 sementes foram distribuídas numa camada única e uniforme, sobre tela de alumínio fixada em caixa de plástico (gerbox), contendo no fundo $40 \mathrm{~mL}$ de água destilada de acordo com Jianhua e McDonald (1996). As caixas foram mantidas de 40 a $45{ }^{\circ} \mathrm{C}$, por 72 horas, com $90 \%$ de UR em câmara de envelhecimento acelerado. Posteriormente foram instalados os testes de germinação (BRASIL, 1992).

O teste de emergência em areia foi realizado com base em Marcos Filho et al. (1987), sob condições de ambiente do laboratório, com quatro repetições de 50 sementes semeadas a $1,5 \mathrm{~cm}$ de profundidade, em caixas plásticas, com teor de água correspondente a $70 \%$ da capacidade de campo. E a avaliação das plântulas emergidas foi efetuada a partir do $4^{\circ}$ dia da semeadura.

A velocidade de emergência foi determinada anotando-se diariamente, a partir da data de inicio da emergência, o número de plântulas que atingiram um estádio pré-determinado. Esse estádio ocorre quando a plântula começa a aparecer na superfície da areia com condições de sobrevivência. A contagem foi feita até que o processo se estabilizasse (MARCOS FILHO et al.,1987).

O teste de condutividade elétrica foi conduzido conforme descrito por Vieira (1994). Nele foram utilizadas quatro subamostras de 50 sementes, por cultivar. Cada subamostra foi pesada e colocada em copos plásticos que continham $75 \mathrm{ml}$ de água destilada e mantida a $25^{\circ} \mathrm{C}$ por 24 horas. A condutividade elétrica da solução foi medida com o uso do condutivimetro, e os valores obtidos foram divididos pelo peso da amostra $(\mathrm{g})$, sendo os resultados expressos em $\mu . \mathrm{cm}^{3}$.

O experimento foi conduzido em delineamento inteiramente casualizado com quatro repetições, em esquema de parcelas subdivididas, tendo como parcelas as variedades e como subparcelas os tempos de armazenamento. A comparação de médias foi feita pelo teste Tukey a $5 \%$ de significância. A análise estatística foi feita pelo programa ESTAT - Sistema para Análise Estatística - U.2.0 (UNIVERSIDADE ESTADUAL PAULISTA, 1991). 


\section{RESULTADOS E DISCUSSÃO}

Para o parâmetro teor de água, a variedade Uirapuru apresentou maior teor nas sementes armazenadas por 15 e 30 dias. Já na variedade Rio Vermelho, o maior teor de água foi observado aos 15 dias de armazenamento (Tabela 1).

Tabela 1 - Média para teor de água e massa de 100 sementes em sementes de feijão 'Uirapuru' do grupo preto e feijão 'Rio Vermelho' do grupo cores, armazenadas por 30 dias a $40{ }^{\circ} \mathrm{C}$ e $76 \%$ de UR

\begin{tabular}{c|c|c|c|c|c|c}
\hline & \multicolumn{3}{|c|}{ Teor de água (\%) } & \multicolumn{3}{c}{ Massa de 100 sementes (g) } \\
\hline \multirow{2}{*}{ Variedade } & \multicolumn{2}{|c|}{ Tempo de armazenamento (dias) } & \multicolumn{3}{c}{$\begin{array}{c}\text { Tempo de } \\
\text { armazenamento (dias) }\end{array}$} \\
\hline & 0 & 15 & 30 & 0 & 15 & 30 \\
\hline Uirapuru & $12,68 \mathrm{bA}$ & $13,36 \mathrm{aA}$ & $13,45 \mathrm{aA}$ & $22,71 \mathrm{bB}$ & $22,69 \mathrm{bB}$ & $23,21 \mathrm{aA}$ \\
\hline Rio Vermelho & $12,11 \mathrm{cB}$ & $13,26 \mathrm{aA}$ & $12,67 \mathrm{bB}$ & $23,52 \mathrm{aA}$ & $23,61 \mathrm{aA}$ & $23,15 \mathrm{bA}$ \\
\hline Média & 12,39 & 13,32 & 13,07 & 23,11 & 23,15 & 23,18 \\
\hline
\end{tabular}

Médias seguidas pela mesma letra, maiúscula na linha e minúscula na coluna, não diferem entre si pelo teste Tukey (a $5 \%$ de significância).

Observa-se, ainda (Tabela 1), que nos tempos 0 e 15 dias, a variedade Uirapuru apresentou menor massa de 100 sementes que a variedade Rio Vermelho. Porém, aos 30 dias, as duas variedades não apresentaram diferenças significativas. Em relação ao tempo de armazenamento, na variedade Uirapuru houve aumento da massa de 100 sementes com o armazenamento, e a variedade Rio Vermelho apresentou comportamento inverso. Isso pode ter ocorrido devido ao aumento no teor de água na variedade Uirapuru, verificado durante o armazenamento, haver exercido influência nesse parâmetro.

As variedades estudadas não apresentaram diferença significativa na porcentagem de germinação. Porém, houve diminuição nessa porcentagem, durante o armazenamento, para ambas as variedades testadas (Tabela 2), e as sementes se apresentaram impróprias para utilização após 30 dias de armazenamento a $40{ }^{\circ} \mathrm{C}$ e $76 \%$ de UR. $76 \%$ de UR teste Tukey (a $5 \%$ de significância).
A manutenção da alta taxa de germinação de sementes de feijão pode ser relacionada com seu armazenamento em teores de água mais reduzidos (LIN, 1988; AGUIRRE e PESKE, 1991; SARTORI, 1996). No presente trabalho verificou-se que ocorreu aumento no teor de água das sementes a partir de 15 dias de armazenamento, o que pode ter influenciado o poder germinativo da semente, o qual foi reduzido após 15 dias de armazenamento. Além disso, o armazenamento por 30 dias a 40 ${ }^{\circ} \mathrm{C}$ e $76 \%$ de UR equivale a um ano de armazenamento em condições ambientais (COELHO et al., 2009), o que explica a perda de poder germinativo após esse período.

Após o envelhecimento acelerado, a variedade Uirapuru apresentou maior germinação que a variedade Rio Vermelho no tempo 0 . No entanto, para ambas as variedades, nos tempos 15 e 30 dias não houve germinação (Tabela 2). Isso pode ter ocorrido porque esse teste de germinação aumenta a taxa de deterioração das sementes, as quais já se encontravam em baixa porcentagem devido ao armazenamento em condições adversas a que foram submetidas no presente experimento. Na tabela 2, observa-se, ainda, que a variedade Uirapuru apresentou maior velocidade de emergência em relação à variedade Rio Vermelho no início do armazenamento, e que após 30 dias em condições de alta temperatura e umidade relativa não houve emergência de plântulas em nenhuma das variedades analisadas.

Tabela 2 - Valores médios para teste de germinação e teste de envelhecimento acelerado; e médias para velocidade de emergência em sementes de feijão 'Uirapuru' do grupo preto e feijão 'Rio Vermelho' do grupo cores, armazenadas por 30 dias a $40{ }^{\circ} \mathrm{C}$ e

\begin{tabular}{c|c|c|c|c|c|c|c|c|c}
\hline & \multicolumn{4}{|c|}{ Germinação (\%) } & \multicolumn{3}{c|}{$\begin{array}{c}\text { Envelhecimento } \\
\text { acelerado (\%) }\end{array}$} & \multicolumn{2}{c}{$\begin{array}{c}\text { Índice de Velocidade de } \\
\text { Emergência (IVE) }\end{array}$} \\
\hline Variedade & \multicolumn{3}{|c|}{ armazenamento (dias) } & \multicolumn{2}{c|}{ armazenamento (dias) } & \multicolumn{2}{c}{ armazenamento (dias) } \\
\hline & 0 & 15 & 30 & 0 & 15 & 30 & 0 & 15 & 30 \\
\hline Uirapuru & $98 \mathrm{aA}$ & $83,5 \mathrm{bA}$ & $20 \mathrm{cA}$ & $93,5 \mathrm{aA}$ & $0 \mathrm{bA}$ & $0 \mathrm{bA}$ & $9,27 \mathrm{aA}$ & $1,38 \mathrm{bA}$ & $0 \mathrm{bA}$ \\
\hline Rio Vermelho & $93 \mathrm{aA}$ & $81 \mathrm{bA}$ & $14,5 \mathrm{cA}$ & $83,5 \mathrm{aB}$ & $0 \mathrm{bA}$ & $0 \mathrm{bA}$ & $5,66 \mathrm{aB}$ & $0,18 \mathrm{bA}$ & $0 \mathrm{~b}$ \\
\hline Média & 95,5 & 82,25 & 17,25 & 88,5 & 0 & 0 & 7,47 & 0,78 & 0 \\
\hline
\end{tabular}

Médias seguidas pela mesma letra, maiúscula na linha e minúscula na coluna, não diferem entre si pelo 
Santos et al. (2005), ao estudarem o comportamento de sementes de feijão de quatro variedades, depois de serem armazenadas por oito meses em condições não controladas de temperatura e umidade relativa, constataram que os valores de germinação reduziram de 5 a $15 \%$, porém se mantiveram dentro dos padrões aceitáveis de germinação, que são de 80 \% (BRASIL, 1992). Porém, armazenando feijão em ambiente não controlado por nove e dezenove meses, Brackmann et al. (2002) encontraram taxas de germinação de 45 e $0 \%$, respectivamente, para feijão do grupo carioca. No presente experimento, aos 30 dias de armazenamento em condições adversas de $40^{\circ} \mathrm{C}$ e $76 \%$ de umidade relativa, as sementes não se encontravam dentro dos padrões aceitáveis.

A variedade Uirapuru apresentou maior condutividade elétrica que a variedade Rio Vermelho. Em ambas as variedades, a condutividade elétrica aumentou aos 30 dias de armazenamento. Isso pode indicar maior nível de danos na semente, o que se observou na emergência e no índice de germinação (Tabela 2). No entanto, apesar de a variedade Uirapuru apresentar maior condutividade elétrica do que a Rio Vermelho, nos demais testes de vigor observou-se que a segunda variedade (Rio Vermelho) apresentou melhores resultados.

Tabela 3 - Média da condutividade elétrica $\left(\mathrm{mS} . \mathrm{s}^{-1}\right)$ em sementes de feijão 'Uirapuru' do grupo preto e feijão 'Rio Vermelho' do grupo cores, armazenadas por 30 dias a $40{ }^{\circ} \mathrm{C}$ e $76 \%$ de UR

\begin{tabular}{c|c|c|c}
\hline \multirow{2}{*}{ Variedade } & \multicolumn{3}{|c}{ Tempo de armazenamento (dias) } \\
\cline { 2 - 4 } & 0 & 15 & 30 \\
\hline Uirapuru & $1173 \mathrm{bA}$ & $803,5 \mathrm{bA}$ & $5613,3 \mathrm{aA}$ \\
\hline Rio Vermelho & $1026,45 \mathrm{bA}$ & $1004,25 \mathrm{bA}$ & $\begin{array}{c}1600,25 \\
\mathrm{aB}\end{array}$ \\
\hline Média & 1099,73 & 903,87 & 3606,77 \\
\hline
\end{tabular}

Médias seguidas pela mesma letra, maiúscula na linha e minúscula na coluna, não diferem entre si pelo teste Tukey (a $5 \%$ de significância).

Binnoti et al. (2005), ao estudarem a condutividade elétrica como um método de avaliação de vigor - tendo como objetivo avaliar o efeito do período de envelhecimento acelerado na lixiviação de íons, proteínas, aminoácidos e açúcares no exsudado do teste da condutividade elétrica e suas relações com a germinação de sementes de feijão da cultivar Pérola - concluíram que estas apresentaram efeito significativo quanto ao período de exposição ao envelhecimento acelerado e que os dados obtidos se ajustaram em regressões polinomiais, pois quanto maior é o período de exposição das sementes a um ambiente adverso com temperatura e idade elevada, maior será a taxa de deterioração dessas sementes, comprovando os resultados obtidos.

\section{CONCLUSÃO}

A variedade Uirapuru apresentou qualidade superior à variedade Rio Vermelho em todos os testes, exceto no teste de condutividade elétrica. As condições de armazenagem em alta temperatura e UR afetaram o desenvolvimento e a qualidade das sementes e, consequentemente, a produção no campo.

\section{REFERÊNCIAS}

AGUIRRE, R.; PESKE, S. T. Seed moisture content required for short term hermetic storage of beans. Seed Science and Technology, v.19, n.1, p.117-122, 1991.

AZEVEDO, M. R. Q. A; GOUVEIA J. P. G.; TROVÃO, D. M. M.; QUEIROGA, V. P. Influência das embalagens e condições de armazenamento no vigor de sementes de gergelim. Revista Brasileira Engenharia Agrícola. Ambiental, v.7, n.3, p.519-524, 2003.

BINOTTI, F. F. S.; HAGA, K. I.; SÁ, M. E.; ARF, O.; SILVA, A. L. Efeito do período de envelhecimento acelerado no teste da condutividade elétrica em sementes de feijão. Embrapa. Disponível em: <http://www.cnpaf.embrapa.br/conafe/pdf/conafe2005-0024.pdf>. Acesso em: 13 nov. 2007.

BRACKMANN, A.; NEUWALD, D. A.; RIBEIRO, N. D.; FREITAS, S. T. Conservação de três genótipos de feijão (Phaseolus vulgaris L.) do grupo carioca em armazenamento refrigerado e em atmosfera controlada. Cienc. Rural, v.32, n.6, p.911-15, 2002.

BRAGANTINI C. Alguns aspectos do armazenamento de sementes e grãos de feijão. Embrapa Arroz e Feijão. Santo Antonio de Goiás. 28p, 2005.

BRASIL. Ministério da Agricultura e Reforma Agrária. Secretaria Nacional de Defesa Agropecuária. Regras para análise de sementes. Brasília, 1992. 
COELHO, S. R. M.; PRUDENCIO, S. H.; NÓBREGA, L. H. P., LEITE, C. F. R Alterações no tempo de cozimento e textura dos grãos de feijão comum durante o armazenamento, Ciência e Agrotecnologia, v. 33, n.2, p. 539-544, 2009.

COMISSÃO ESTADUAL DE SEMENTES E MUDAS. Recomendações técnicas para o cultivo de feijão no Rio Grande do Sul. Santa Maria: PALLOTTI, 2000. 80p.

EMBRAPA. Cultivo do feijão irrigado na região noroeste de Minas Gerais. Sistemas de Produção n.5, ISSN 1679-8869. Dezembro/2005. Disponível em: $<$ http://sistemasdeproducao.cnptia.embrapa.br/FontesHTML/Feijao/FeijaoIrrigadoNoroesteMG/index.htm>. Acesso em: 15 set. 2008.

FRANSCISCO, F.G. Avaliação da qualidade sanitária e fisiológica de sementes de feijão, com diferentes graus de umidade, em armazenamento hermético a temperaturas constantes. Universidade Estadual de Campinas. Dissertação de mestrado, 2001.

FRANCISCO, F.G.; USBERTI, R.; TONELI, J.T.C.L. Ajuste de isotermas de sorção de sement'es de cultivares de feijoeiro. Revista Brasileira de Sementes, Pelotas, vol. 29, $\mathrm{n}^{\circ} 1$, p.35-39, 2007.

JIANHUA, Z.; MCDONALD, N. B. The saturated salt accelerated aging test for small-seeded crops. Seed Science and Technology, v.25,n.2, p.123-131, 1996.

LIN, S. S. Efeito do período de armazenamento na lixiviação eletrolítica dos solutos celulares e qualidade fisiológica da semente de milho (Zea mays L.) e feijão (Phaseolus vulgaris L.). Revista Brasileira de Sementes, v.10, n.3, p.59-67, 1988.

MARCOS FILHO, J.; CÍCERO, S. M.; SILVA, W. R. Avaliação da qualidade das sementes. Piracicaba: FEALQ, 1987.

MARINO, R. H.; MESQUITA, J. B. Micoflora de sementes de feijão comum (Phaseolus vulgaris L.) provenientes do Estado de Sergipe. Revista Brasileira de Ciências Agrárias v.4, n.3, p.252-256, 2009.

MENTEN, J. O. M.; MORAES, M. H. D.; NOVEMBRE, A. D. L. C.; ITO, M. F. Qualidade das sementes de feijão no Brasil, 2006. Artigo em hipertexto. Disponível em: $<$ http:// www.infobibos.com/artigos/2006_2/sementesfeijão/index. htm>. Acesso em 20 mar. 2007.

NOVEMBRE, A.D.L.C.; MARCOS-FILHO, J. Tratamento fungicida e conservação de sementes de feijão. Revista Brasileira de Sementes, Brasília, v.13, n.2, p.105-113, 1991.

ROSSETO, C. A. V.; NOVEMBRE, A. D. L. C.; MARCOS FILHO, J.; SILVA, W. R.; NAKAGAWA, J. Efeito da disponibilidade hídrica do substrato, da qualidade fisiológica e do teor de água inicial das sementes de soja no processo de germinação. Scientia Agrícola, v.54, n.2, p.97-105, 1997.
SANTOS, C. M. R.; MENEZES, N. L.; VILLELA, F. A. Teste de deterioração controlada para avaliação do vigor de sementes de feijão. Revista Brasileira de Sementes, v. 25, n.2, p.28-35, 2003.

SANTOS, C. M. R; MENEZES, N. L.; VILLELA, F. A. Alterações fisiológicas e bioquímicas em sementes de feijão envelhecidas Revista Brasileira de Sementes, v.26, n.1 p. 110-119, 2005.

SARTORI, M. R. Armazenamento: In: ARAUJO, R. S. et al. Cultura do Feijoeiro Comum no Brasil. Piracicaba: POTAFOS, p.543-560, 1996.

SIQUEIRA, J. L.; KIKUTI, H.; GARCIA, J. C.; MARINHO, J. T. S. Emergência e vigor de sementes de feijoeiro em função de safras e períodos de armazenamento. Disponível em: $<$ http://www.editora.ufla.br/revista/25_1/art23.pdf $>$. Acesso em: 15 out. 2007.

UNIVERSIDADE ESTADUAL PAULISTA. Sistema para análise estatística. ESTAT U.2.0. Jaboticabal, UNESP, 1991.

VIEIRA, R. D. Teste de condutividade elétrica. In: Vieira, R. D.; Carvalho, N. M. (Eds.). Testes de vigor em sementes. Jaboticabal: FUNEP, 1994. p. 103-132. 